GAD activity was corrected for the CSF space and the corrected GAD activity was significantly lower in senile dementia than in control subjects.

\section{Vasopressin (AVP)}

Besides the antidiuretic activity, AVP enhances a cognitive function. AVP was detected in $60 \%$ of the cerebral cortex of autopsied brains of control subjects, although the content was not high. However, AVP was detected less frequently in the cortex of patients with senile dementia. No age-related change was observed in AVP content in the cortex.

\section{Conclusion}

Table 1 summarizes age-related changes and abnormalities of neurotransmitters in Alzheimer's disease and senile dementia. Neurotransmitters exhibit various mode of changes with the age. Abnormalities found in Alzheimer's disease or senile dementia are not always parallel to the age-related changes. These results suggest that Alzheimer's disease or senile dementia cannot be understood as an accelerated senescence, but another etiological factor might be introduced for the manifestation of such dementia. Moreover, the disturbance in neurotransmitters reveals a discrepancy between Alzheimer's disease and senile dementia, indicating that further investigations should be carried out taking the age of onset into consideration.

Table 1. Age-related changes and abnormalities of neurotransmitters in Alzheimer's disease and senile dementia

\begin{tabular}{|l|l|c|c|c|c|}
\hline Neurons & Enzymes, Cofactor, Metabolite & Material & Aging & $\begin{array}{c}\text { Alzheimer's } \\
\text { disease }\end{array}$ & $\begin{array}{c}\text { Senile } \\
\text { dementia }\end{array}$ \\
\hline Acetylcholine (Ach) & Choline acetyltransferase (CAT) & $\begin{array}{c}\text { Autopsied } \\
\text { brain }\end{array}$ & $\downarrow$ & $\downarrow \downarrow$ & $\downarrow$ \\
& Acetylcholine esterase (ACE) & CSF & $\uparrow$ & $\downarrow$ & $\rightarrow$ \\
Dopamine (DA) & Homovanillic acid (HVA) & CSF & $\downarrow$ & $\downarrow$ & $\downarrow$ \\
Norepinephrine (NE) & Detrahydrobiopterin (H.BP) & CSF & $\downarrow$ & $\downarrow$ & $\sim$ \\
& Dopamine- $\beta$-hydroxylase (DBH) & CSF & $\rightarrow$ & $\downarrow$ & $\downarrow$ \\
Serotonin (SE) & "-Hydroxyindoleacetic acid (5-HIAA) & CSF & $\rightarrow$ & $\downarrow$ & $\downarrow$ \\
GABA & Glutamic acid decarboxylase (GAD) & CSF & $\downarrow$ & & $\sim$ \\
Vasopressin & Arginine-vasopressin (AVP) & Autopsied & $\rightarrow$ & & $\sim$ \\
& & brain & & & $\downarrow$ \\
\hline
\end{tabular}

\title{
3. Aging and Host Responses: Infection
}

\author{
Kaoru Shimada \\ Institute of Medical Science, University of Tokyo
}

Infection is a quite complicated biological phenomenon elicited by the interactions between host and parasites. This paper presents two different studies on the biological responses of elderly persons to infection. The first one is a study on the responses to the vaccine. Vaccination offers a unique opportunity to give a fixed amount of certain bacterial antigen to the host, which provides excellent comparison of host resonses between younger adults and elderly persons. The second one is a study on elderly patients with bacteremia. Bacteremia is one of the overwhelmingbacterial infections usually accompanied with chills and high fever. However, there are observations 
that some geriatric patients with bacteremia were afebrile at the onset of the illness ${ }^{1}$, suggesting deterioration in various homeostatic control system in the aged. In this study, we defined the incidence of septic shock, its mortality, and of afebrile bacteremia among patients with bacteremia. In addition, we compared febrile and afebrile patients with bacteremia using several clinical and laboratory variables.

Effect of aging on the host responses to the vaccination.

Antibody response and adverse reactions were determined on 196 subjects vaccinated with 14 valent pneumococcal polysaccharide vaccine. Age distribution of the subjects were as follows: 49 adult volunteers with $20-49$ years of age, 48 nursing home residents with 50-79 years of age and 99 nursing home residents with 80 years or older. Adverse reactions were observed mostly in younger adult group and very few in older persons. In 20-49 years of age group, headache, malaise and myalgia/arthralgia were observed in $81 \%, 72 \%$ and $61 \%$, respectively. No subject in 50-79 years of age group claimed such symptoms. In 80 years of age or older group, fatigue, headache and malaise were found in $1-2 \%$. Local reactions, generally erythema and induration with or without tenderness, are more common in the younger adults group (47-90\%) than in other two aged groups $(2-17 \%)$. The severity of both systemic and local reactions after vaccination was milder in the 50-79 years and in 80 years or older groups. Antibody titers were determined by a radioimmunoassay in 50 subjects randomly selected in each age group.

The 50-79 years of age group had the highest prevaccination levels of antibody in 12 serotypes. The 80 years of age or older group had the lowest preimmunization antibody titer in 9 serotypes. In comparison with prevaccination levels of antibody in the American adults ${ }^{2)}$, almost all the Japanese subjects in this study had higher prevaccination antibody titers for every 14 polysaccharide types. Good antibody response to the vaccine were noted in nearly all of the subjects, even in a group of 80 years or older. Among three age groups, there is no significant difference in the mean fold increase in the antibody levels to the polysaccharides, and in the percentages of persons showing two-fold or greater increase in titer. It is interesting to note that elderly persons showed good antibody responses with rare adverse reactions to vaccine.

Local reaction was Arthus-like and might have been caused by a response to local antigen-antibody union at the site of injection. Data from investigations, in which determinations of the circulating antibody titers to S. pneumoniae and the degree of local reactions to polyvalent pneumococcal polysaccharide vaccine were examined, generally agree the Arthus explanation for such local reactions. Since no significant difference was moted in the prevaccination antibody titers or in the antibody responses among 3 age groups, it can be assumed that the low incidence of local reactions in the elderly persons reflects the reduction in Arthus-type reactions in the aged.

\section{Elderly patients with bacteremia}

1) Aging and septic shock

Incidence and mortality rate of septic shock were determined on 310 elderly patients with septicemia. Shock occurs approximately in $20 \%$ of the patients with septicemia under 65 years

Table 1. Clinical and laboratory features of elderly patients with septicemia

\begin{tabular}{|c|c|c|c|}
\hline $\begin{array}{l}\text { Max. tem- } \\
\text { perature at } \\
\text { the onset of } \\
\text { bacteremia }\end{array}$ & $\begin{array}{c}\leqq 37.9^{\circ} \mathrm{C} \\
(87)\end{array}$ & $\begin{array}{c}38.0^{\circ} \mathrm{C} \\
(213)\end{array}$ & \\
\hline Malignancy & 22 & 65 & n.s. \\
\hline Septic shock & 22 & 57 & n.s. \\
\hline $\begin{array}{l}\text { Antibiotic } \\
\text { therapy } \\
\text { prior to } \\
\text { the onset }\end{array}$ & 32 & 64 & n.s. \\
\hline WBC & $12.858 \pm 9100$ & $11.903 \pm 10.102$ & n.s. \\
\hline $\begin{array}{l}\text { WBC } \\
\qquad(>10.000)\end{array}$ & $41 / 84$ & $97 / 212$ & n.s. \\
\hline $\begin{array}{l}\text { Serum } \\
\text { protein }\end{array}$ & $5.8 \pm 0.9$ & $6.0 \pm 0.4$ & n.s. \\
\hline $\begin{array}{l}\text { Serum } \\
\text { protein } \\
(<5.0)\end{array}$ & $17 / 83$ & $16 / 155$ & $\mathrm{p}<0.025$ \\
\hline
\end{tabular}


of age, and in $30 \%$ of the patients of $66-90$ years of age. Fatality rates increase with aging; of $23 \%$ among patients with septic shock under 75 years old and of $50 \%$ among those over 76 years old $(\mathrm{p}<0.05)$.

2) Afebrile bacteremia in elderly patients

Afebrile bacteremia was detected in 87 of 310 elderly patients. The afebrile state was defined as the failure of the body temperature to mount greater than $37.9^{\circ} \mathrm{C}$ in the day when the blood cultures were performed. Afebrile bacteremia occurred more frequently among patients over 81 years old, with 33 of the 92 patients identified, compared with 54 of the 218 patients under 80 years old $(\mathrm{p}<0.1$ ). Table 1 lists associated medical illnesses, leucocyte count and serum protein of the patients with febrile and afebrile bacteremia. No significant difference was noted concerning the microbiological features of blood isolates, or the infectious disorders precipitating the bacteremia among patients with febrile and afebrile bacteremia. Bacteremia in the elderly were not invariably accompanied with a peripheral blood leucocytosis and were not trivial event. Hypoproteinmeia, as defined by a serum protein concentration, that does not exceed $5 \mathrm{~g} / \mathrm{dl}$, occurred in 17 of the 83 patients with afebrile bacteremia. This contrasts with the frequency among patients with febrile bacteremia whose serum protein concentration was determined at the onset of the illness $(p<0.025)$. Correlation between serum protein concentration in patients with bacteremia and their fever response is shown in Fig. $1(\mathrm{p}<0.025)$.

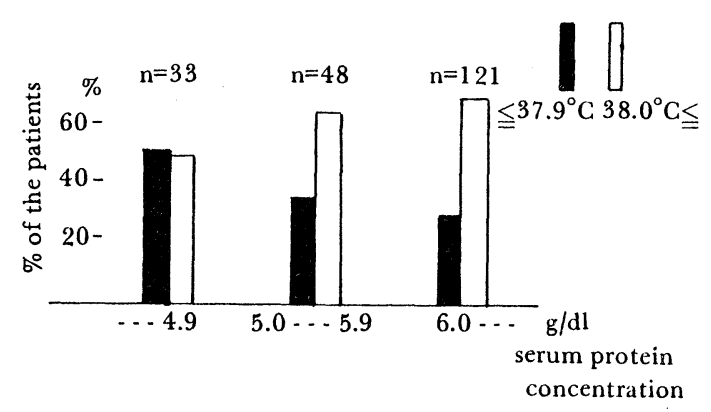

Fig. 1. Relationship between serum protein concentration and maximum temperature at the onset of bacteremia.

\section{SUMMARY}

Infection in elderly presons often presents without the typical symptoms found in younger age groups. With age increasing, there comes deterioration in various homeostatic control system in the body, which may cause paucity of signs in elderly patients. However, changes of biological responses that occur with aging are too complex: some responses are retained regardless to aging (antibody response to the booster), while others deteriorate rapidly (Arthus-type reaction). Furthermore, the elderly persons often have a severely debilitaing illness, which leads to reduce host reactions (afebrile bacteremia). Studies on the biological responses of elderly persons with infection are very scanty. Far more researches would be desirable in this field.

\section{REFERENCES}

1) Gleckman $R$, et al: Afebrile bacteremia, a phenomenon in geriatric patients. JAMA 248: 1478, 1982.

2) Weibel RE, et al: Studies in human subjects of polyvalent pneumococcal vaccines (39894). Proc Soc Exp Biol Med 156: 144, 1977. 